\title{
Cortical Cerebral Blood Flow, Oxygen Extraction Fraction, and Metabolic Rate in Patients with Middle Cerebral Artery Stenosis or Acute Stroke
}

\author{
(1)Z. Liu and 가. Li
}

\begin{abstract}
BACKGROUND AND PURPOSE: With the advances of magnetic resonance technology, the CBF, oxygen extraction fraction, and cerebral metabolic rate of oxygen can be measured in MRI. Our aim was to measure the CBF, oxygen extraction fraction, and cerebral metabolic rate of oxygen use in patients with different severities of middle cerebral artery stenosis or acute stroke by using the arterial spin-labeling and susceptibility-weighted imaging techniques.
\end{abstract}

MATERIALS AND METHODS: Fifty-seven patients with MCA stenosis or acute stroke were recruited and classified into 4 groups: mild MCA stenosis (group 1), severe MCA stenosis (group 2), occluded MCA (group 3), and acute stroke (group 4). Arterial spin-labeling and SWI sequences were used to acquire $\mathrm{CBF}$, oxygen extraction fraction, and cerebral metabolic rate of oxygen.

RESULTS: The oxygen extraction fraction in hemispheres with mild MCA stenosis (group 1) was remarkably higher than that in the contralateral hemisphere. In addition, hemispheres with severe MCA stenosis (group 2) had significantly lower CBF and a significantly higher oxygen extraction fraction than the contralateral hemisphere. Hemispheres with occluded MCA (group 3) or acute stroke (group 4) had a significantly lower CBF and cerebral metabolic rate of oxygen and a significantly higher oxygen extraction fraction than the contralateral hemisphere.

CONCLUSIONS: The oxygen extraction fraction gradually increased in groups 1-3. When this offset a decrease in CBF, the cerebral metabolic rate of oxygen remained at a normal level. An occluded MCA led to reduction in both the CBF and cerebral metabolic rate of oxygen. Moreover, the oxygen extraction fraction and cerebral metabolic rate of oxygen significantly increased and decreased, respectively, in the occluded MCA region during acute stroke.

ABBREVIATIONS: $\mathrm{ASL}=$ arterial spin-labeling; $\mathrm{Hct}=$ hematocrit; $\mathrm{CMRO}_{2}=$ cerebral metabolic rate of oxygen; $\mathrm{HR}=$ high-resolution; OEF = oxygen extraction fraction; $\mathrm{rCBF}=$ relative cerebral blood flow; $\mathrm{rCMRO}_{2}=$ relative cerebral metabolic rate of oxygen; rOEF = relative oxygen extraction fraction; $Y_{\mathrm{v}}=$ venous oxygen saturation

A reduction in cerebral blood flow in brain tissue is typically accompanied by a compensatory increase in the oxygen extraction fraction (OEF) to maintain normal neuronal function. ${ }^{1}$ However, the risk of stroke is greatly increased once the maximum OEF is achieved. ${ }^{2}$ The presence of increased OEF in stroke is an independent predictor of subsequent stroke in patients. ${ }^{3,4}$ Consequently, both CBF and OEF are important indicators for stroke; however, neither parameter sufficiently predicts the risk of this condition. It is possible to use both parameters and the arterial oxygen content to derive cerebral metabolic rate of oxygen

Received April 20, 2015; accepted after revision August 9.

From the Department of Medical Imaging (Z.L.), First Hospital of Nanchang City, The Third Affiliated Hospital of Nanchang University, Nanchang City, China; and Department of Preventive Medicine (Y.L.), Heze Medical College, HeZe, Shandong, China.

Please address correspondence to Zhenghua Liu, MD, Department of Medical Imaging, First Hospital of Nanchang City, The Third Affiliated Hospital of Nanchang University, Nanchang City 330006, China; e-mail. wuxiaoshui@126.com

http://dx.doi.org/10.3174/ajnr.A4624
$\left(\mathrm{CMRO}_{2}\right)$ use, which is of critical importance in the occurrence of stroke. $^{1}$

Positron-emission tomography provides the most accurate in vivo $\mathrm{OEF}$ and $\mathrm{CMRO}_{2}$ measurements; however, it is expensive and requires administration of radioactive isotopes. Both OEF and CBF can be determined using MR susceptometry and arterial spin-labeling (ASL). ${ }^{5,6}$ MR susceptometry uses gradient-echo phase maps to estimate oxygen saturation in segments of the jugular and gray matter veins. ${ }^{7,8}$ This technique requires blood vessels to have a substantially greater length than the diameter. ${ }^{7,8}$ Susceptibility-weighted imaging is a type of MR susceptometry that can obtain measurements of venous oxygen saturation by using the phase difference between the venous blood and surrounding tissue. ${ }^{9,10}$ ASL is a noninvasive technique that can measure $\mathrm{CBF} .{ }^{11,12}$ The gray matter $\mathrm{CMRO}_{2}$ can be obtained from local CBF and OEF measurements.

Most previous PET studies have focused on OEF and $\mathrm{CMRO}_{2}$ in patients with an occluded carotid artery; few studies have in- 
Table 1: Number, age, clinical characteristics, Hct, and $\mathrm{Hb}$ of the healthy subjects and patients

\begin{tabular}{|c|c|c|c|c|c|c|c|}
\hline Groups & No. & $\begin{array}{c}\text { Age } \\
\text { Range } \\
\text { (yr) }\end{array}$ & $\begin{array}{c}\text { Mean } \\
\text { Age } \\
(y r)\end{array}$ & $\begin{array}{l}\text { Males } \\
\text { (No.) }\end{array}$ & $\begin{array}{l}\text { Females } \\
\text { (No.) }\end{array}$ & Het $\left(\times 10^{-2}\right)$ & $\mathrm{Hb}$ \\
\hline $\begin{array}{l}\text { Healthy subjects } \\
\text { Mild stenotic MCA }\end{array}$ & 10 & $40-67$ & 55.9 & 5 & 5 & $34.9 \pm 12.6$ & $13.1 \pm 1.2$ \\
\hline $\begin{array}{l}\text { Group } 1 \\
\text { Severe stenotic MCA }\end{array}$ & 13 & $37-65$ & 50.4 & 6 & 7 & $40.2 \pm 4.9$ & $14.2 \pm 1.4$ \\
\hline $\begin{array}{l}\text { Group } 2 \\
\text { Occluded MCA }\end{array}$ & 11 & $45-75$ & 58.0 & 6 & 5 & $39.2 \pm 5.1$ & $13.1 \pm 2.1$ \\
\hline $\begin{array}{l}\text { Group } 3 \\
\text { Patients with acute stroke }\end{array}$ & 16 & $36-72$ & 58.5 & 8 & 8 & $39.8 \pm 4.4$ & $13.8 \pm 2.3$ \\
\hline Group 4 & 17 & $38-73$ & 57.6 & 9 & 8 & $40.3 \pm 6.6$ & $13.6 \pm 2.1$ \\
\hline
\end{tabular}

Note:- Hb indicates hemoglobin.

vestigated the stenotic or occluded middle cerebral artery. ${ }^{13,14}$ To the best of our knowledge, no studies have assessed $\mathrm{CBF}, \mathrm{OEF}$, and $\mathrm{CMRO}_{2}$ relative to the degree of MCA stenosis. To address this question, we measured $\mathrm{CBF}, \mathrm{OEF}$, and $\mathrm{CMRO}_{2}$ in patients with different degrees of MCA stenosis or stroke via ASL and susceptibility-weighted phase imaging.

\section{MATERIALS AND METHODS \\ Subjects}

This prospective study was approved by the institutional review board, and written informed consent was obtained from all subjects or their guardians. Ten healthy volunteers ( 5 men, 5 women) with a mean age of 55.9 years (age range, 40-67 years) were enrolled in the study. All volunteers had normal findings on neurologic examination and brain MR imaging, no stenotic middle cerebral or carotid artery, and no history of neurologic disease.

Eighty-four patients with MCA stenosis or acute stroke were recruited in the study and underwent clinical evaluation, laboratory testing, MR imaging examination, and color Doppler sonography to assess the cervical vasculature. Inclusion criteria were as follows: 1) unilateral stenosis of the M1 segment of the MCA or unilateral acute MCA stroke, 2) no stenosis in the internal carotid and/or common carotid artery, 3) no extracranial-intracranial vessel bypass operation, and 4) no motion artifacts in the susceptibility-weighted or ASL images. Periodic stripe-like artifacts in the phase-code direction of the images were identified as motion artifacts. One and 5 patients were excluded due to motion artifacts and bilateral MCA stenosis, respectively. Six patients were excluded because no sonographic examination of the cervical vasculature had been performed, and 10 patients were excluded because arteriosclerosis was found in the internal carotid and/or common carotid artery by color Doppler ultrasongraphy. Five patients were excluded because 5 veins were not detected in the SWIs in a unilateral hemisphere. Subsequently, 57 patients ( 29 men, 28 women) with a mean age of 55.9 years (age range, 37-75 years) were included in the study. Nine patients had a history of hypertension, 6 had diabetes mellitus, and 4 had both comorbidities. Fourteen patients had an acute unilateral MCA stroke. The time between symptom onset and MR imaging examination in patients with acute stroke was between 12 and 65 hours, with a median of 32 hours. All subjects and patients underwent measurements for hemoglobin (grams per deciliter) and hematocrit (Hct) levels within 3 days of MR imaging examinations.

\section{Patient Categorization}

Classification of the degree of MCA stenosis was based on the diameter of the vessel at the point of maximal narrowing relative to the normal distal lumen diameter, which was obtained from high-resolution (HR) T2-weighted images. For data analysis, MCA stenosis was graded as mild $(<50 \%$ diameter reduction) or severe ( $>50 \%$ diameter reduction) stenosis or occlusion.

Patients were divided into 4 groups: 3 without and 1 with stroke (Table 1). Patients without stroke were classified according to the degree of MCA narrowing: mild MCA stenosis (group 1), severe MCA stenosis (group 2), and occluded MCA (group 3). All patients had normal findings on brain MR imaging, except on the MR angiography, with an acceptable level of white matter abnormalities (ie, pencil-thin lining of periventricular hyperintensity and foci of high signal intensity in the deep white matter) for subjects older than 60 years of age. The white matter abnormalities were not high signals in the diffusion-weighted images. The lesions in these patients with acute stroke were located in the region of the MCA. The number, age, and clinical characteristics of the various subgroups are listed in Table 1 .

\section{MR Imaging Measurements}

All MR imaging examinations were performed on a 3T whole-body scanner (Signa HDxt; GE Healthcare, Milwaukee, Wisconsin) with an 8-channel head coil. The MR imaging acquisition protocols included axial T2-weighted imaging, diffusion-weighted imaging, 3D time-of-flight MRA, HR-T2WI, SWI, and pulsed-continuous ASL. The total scan time for each patient was approximately 18 minutes.

T2WI parameters were as follows: TR, $9600 \mathrm{~ms}$; TE, $117 \mathrm{~ms}$; TI, $2400 \mathrm{~ms}$; section thickness, 6 and $1.0 \mathrm{~mm}$ gap between sections; FOV, $24 \times 24 \mathrm{~cm}^{2}$; matrix size, $288 \times 256$; and NEX, 2 . Axial single-shot spin-echo echo-planar sequences were used to acquire DWI with the following parameters: TR/TE, 4000/70 ms; $\mathrm{b}$ factors, 0 and $1000 \mathrm{~s} / \mathrm{mm}^{2}$; matrix size, $128 \times 128$; FOV, $24 \times 24$ $\mathrm{cm}^{2}$; NEX, 4; section thickness, $6 \mathrm{~mm}$; and section gap. $1 \mathrm{~mm}$.

3D TOF MRA was performed with the following parameters: TR/TE, 20/3.4 ms; flip angle, $20^{\circ}$; FOV, $22 \times 22 \mathrm{~cm}^{2}$; matrix size, $384 \times 192$; and section thickness, $1.6 \mathrm{~mm}$. The HR-T2WI sequence was perpendicular to the stenotic M1 segment of the MCA shown on 3D TOF MRA. HR-T2WI sequence parameters were as follows: TR/ TE, 2800/60 ms; FOV, $12 \times 12 \mathrm{~cm}^{2}$; matrix size, $512 \times 256$; section thickness, $2 \mathrm{~mm}$; section gap, $0.5 \mathrm{~mm}$; and NEX, 4 . Figure 1 shows representative MRA and HR-T2WI findings.

A 3D single-shot fast spin-echo with an in-plane spiral readout acquisition was performed to generate the quantitative $\mathrm{CBF}$ maps for ASL. The ASL pulse parameters were the following: point, 512; arm, 8; postlabeling delay, $2025 \mathrm{~ms}$; NEX, 3; FOV, $22 \times 22 \mathrm{~cm}^{2}$; spatial resolution, $3.4 \times 3.4 \times 2 \mathrm{~mm}^{3}$; section thickness, $2.0 \mathrm{~mm}$; scan locations, 44 ; and bandwidth, 62.5 . The acquisition time was 4 minutes 26 seconds.

For axial 3D SWI, a fully flow-compensated 3D fast low-angle shot sequence was used with the following parameters to obtain 


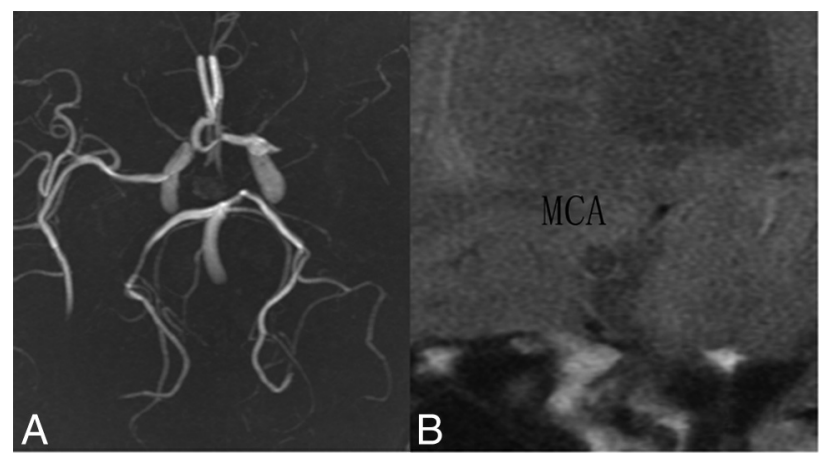

FIG 1. Representative MR angiography and high-resolution T2weighted imaging findings. A, 3D time-of-flight MRA reveals an occlusive left middle cerebral artery. $B$, Plaque with heterogeneous signal intensity was present in the MCA lumen on HR-T2WI.

the OEF: TR/TE, 55.9/12.1 ms; NEX, 1; matrix, $448 \times 384$; flip angle, $15^{\circ}$; and FOV , $22 \times 22 \mathrm{~cm}^{2}$. The acquisition time was 6 minutes 50 seconds.

After acquisition, the magnitude and phase images were reconstructed. The phase images were processed with high-pass filtering to remove unwanted phase shifts (field variations) from the main magnet. ${ }^{9}$

\section{Theory}

The principle of MR susceptometry is based on the measurement of differences in susceptibility between a candidate cerebral vein and its surroundings as obtained from axial phase images. ${ }^{15}$ The cerebral veins can be approximated as infinitely long cylinders parallel to a static magnetic field. The differences in susceptibility between the vein and tissue manifest as ${ }^{9}$ :

1) $\Delta \varphi_{\text {vein-tissue }}=2 \pi \times \gamma \times \Delta \chi_{\text {vein-tissue }}$

$$
\times\left(\cos ^{2} \theta-1 / 3\right) \times \mathrm{B}_{0} \times \mathrm{TE},
$$

where $\gamma$ is the gyromagnetic ratio, TE is the echo time, $\mathrm{B}_{0}$ is the main magnetic strength, and $\theta$ is the angle between the vein and $\mathrm{B}_{0}$. Meanwhile, $\Delta \chi_{\text {vein-tissue }}$ is the susceptibility shift between the vein and tissue, as follows ${ }^{9,16}$ :

$$
\Delta \chi_{\text {vein-tissue }}=\Delta \chi_{\text {do }} \times \operatorname{Hct} \times\left(1-Y_{v}\right),
$$

where $\Delta \chi_{\text {do }}$ (deoxygenated blood) is $0.27 \mathrm{ppm},{ }^{15} \mathrm{Hct}$ is the blood hematocrit, and $Y_{\mathrm{v}}$ is the venous oxygen saturation. Under normal conditions, arterial oxygen saturation is nearly $100 \%$. Consequently, OEF can be approximated as OEF $=1-Y_{\mathrm{v}} \cdot{ }^{9}$

$\mathrm{CBF}$ was calculated by using the following equation ${ }^{17}$ :

3) $\mathrm{CBF}=\lambda\left[1-\exp \left(-\mathrm{T}_{\text {sat }} / \mathrm{T}_{\text {lgm }}\right)\right]$

$$
\times \frac{\exp \frac{\mathrm{W}}{\mathrm{T} 1 \mathrm{~B}}}{2 \alpha \mathrm{T} 1 \mathrm{~B}\left[1-\exp \left(-\frac{\tau}{\mathrm{T} 1 \mathrm{~B}}\right)\right]} \times \frac{\Delta \mathrm{S}}{\mathrm{SO}}
$$

where the partition coefficient, $\lambda$, is 0.9 ; the time of saturation performed before imaging, $\mathrm{T}_{\text {sat }}$, is 2.0 seconds; the longitudinal relaxation time ( $\mathrm{T} 1$ ) of gray matter for $3 \mathrm{~T}, \mathrm{~T}_{1 \mathrm{gm}}$, ${ }^{18}$ is 1.2 seconds; the postlabel delay, $\mathrm{W}$, is 2.0 seconds; the longitudinal relaxation time (T1) of blood for $3 \mathrm{~T}, \mathrm{~T} 1 \mathrm{~B},{ }^{18}$ is 1.4 seconds; the labeling

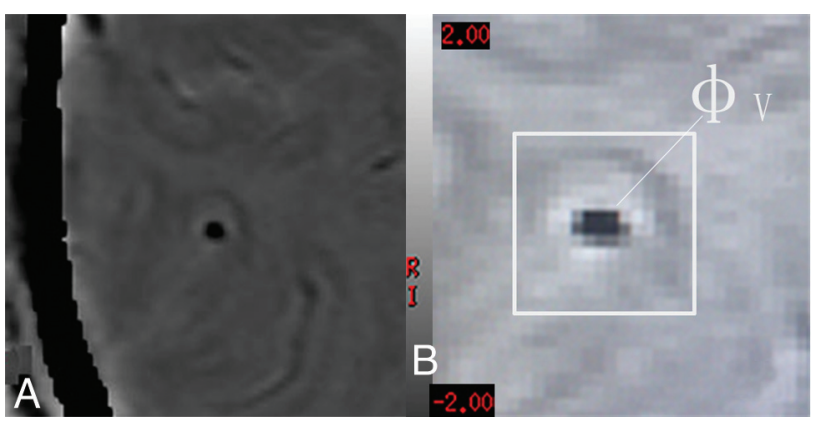

FIG 2. Illustration of MR susceptometry for determining $Y_{\mathrm{v}} . A, A$ phase image obtained from susceptibility-weighted imaging. $B$, Zoomed view of the phase image for the gray matter, with the vein as the representative phase value within the vessel. The rectangle shows the ROI of the gray matter, including the vein.

efficiency, which is a combination of both label pseudocontinuous ASL (0.8) and background suppression (0.75), $\alpha$, is $0.6(0.8 \times$ $0.75)$; the labeling time, $\tau$, is 1.5 seconds; $\Delta S$ is the difference between the reference and labeled image signal intensities; and $\mathrm{SO}$, the signal intensity of the proton density-weighted reference image.

Oxygen consumption manifests as ${ }^{16}$ :

$$
\mathrm{CMRO}_{2}=\left(Y_{\mathrm{a}}-Y_{\mathrm{v}}\right) \times \mathrm{CBF} \times \mathrm{C}_{\mathrm{a}},
$$

where $Y_{\mathrm{a}}$ is the arterial oxygen saturation approximated as $1, \mathrm{CBF}$ is brain-blood perfusion, and $C_{a}$ is the oxygen concentration of blood per $100 \mathrm{~mL}$. $C_{\mathrm{a}}$ is determined by using the hemoglobin level and $\mathrm{O}_{2}$ carrying capacity per gram of hemoglobin. For a healthy person, this is $55.6 \mu \mathrm{mol} \mathrm{O}{ }_{2}{ }^{16}$ In this study, we obtained the $\mathrm{CMRO}_{2}$ by measuring $Y_{\mathrm{v}}$ in the gray matter candidate veins by using SWI and determining the local CBF in the region supplied by the MCA by using ASL.

\section{Image Processing}

Susceptibility-weighted and ASL images were transferred to the workstation (AW4.4, GE Healthcare) for postprocessing. SWI was reconstructed as axis magnitude and phase images. High-pass filtering $(32 \times 32$ Hanning $)$ was performed on the phase images to remove variance in the background field.

The phase value measurements of the candidate vein $\left(\varphi_{\mathrm{V}}\right)$ and surrounding tissue $\left(\varphi_{\mathrm{T}}\right)$ were based on methods proposed by Fan et $\mathrm{al}^{16}$ and Fujima et al. ${ }^{19} \varphi_{\mathrm{V}}$ and $\varphi_{\mathrm{T}}$ were measured in ROIs by using a square ROI $(20 \times 20$ pixels $)$ containing the gray matter candidate vein placed on the phase image (Fig 2). When the length of the vessel exceeds $6 \times$ its diameter, it can be fitted to the longcylinder model in MR susceptometry. ${ }^{8}$ Consequently, we selected veins that had a length of at least $6 \times$ their diameter. The orientation of the vein in the gray matter was verified as parallel to $B_{0}$ by tracing the vessel through several adjacent axial, sagittal, and coronal sections. The sagittal and coronal sections were reconstructed from the phase axis section. When there was a tilt angle of the vein, it was calculated as follows ${ }^{8}$ :

$$
\theta=\tan ^{-1}\left\{\sqrt{\left[(x 1-x 2)^{2}+(y 1-y 2)^{2}\right] / \Delta z^{2}}\right\},
$$

where $x 1$ and $y 1$ are the coordinates of the vein measured for phase in the axis section, $x 2$ and $y 2$ are the coordinates of the vein 


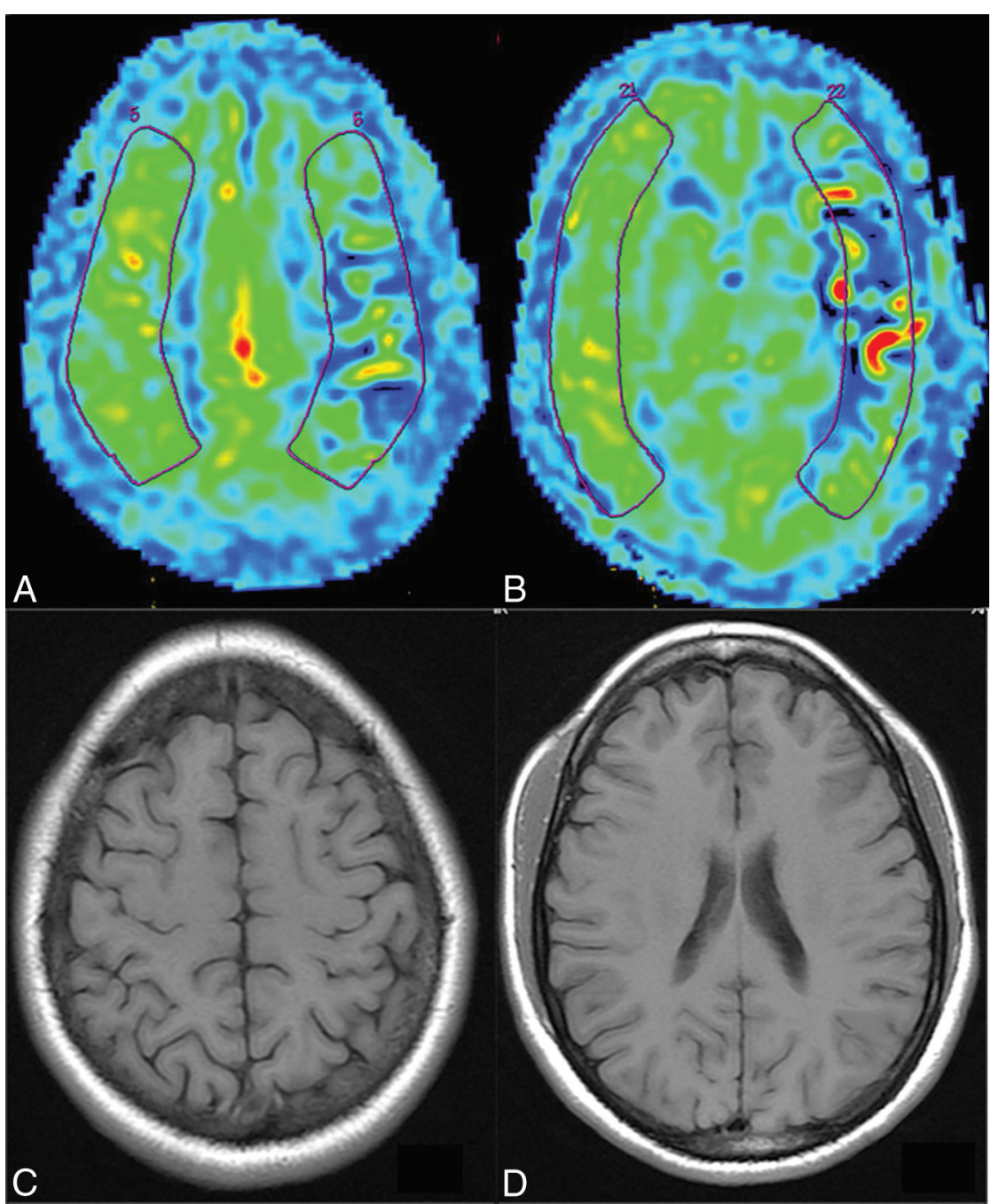

FIG 3. Placement of the ROI for cerebral blood flow measurements on an arterial spin-labeling CBF map. The ROI was positioned from the top $(A)$ to the level of the thalami $(B)$ in a 50 -year-old patient with an occlusive MCA. $C$ and $D$, Anatomic images corresponding to $A$ and $B$.

Table 2: Statistical results for the CBF, OEF, and $\mathrm{CMRO}_{2}$ in healthy subjects

\begin{tabular}{|c|c|c|c|c|c|c|}
\hline & \multicolumn{2}{|c|}{$\mathrm{CBF}(\mathrm{mL} / 100 \mathrm{~g} / \mathrm{min})$} & \multicolumn{2}{|c|}{ OEF (\%) } & \multicolumn{2}{|c|}{$\mathrm{CMRO}_{2}(\mu \mathrm{mol} / 100 \mathrm{~g} / \mathrm{min})$} \\
\hline & Left & Right & Left & Right & Left & Right \\
\hline & $53.4 \pm 8.6$ & $54.4 \pm 9.6$ & $36.8 \pm 3.1$ & $37.4 \pm 3.3$ & $146.8 \pm 29.7$ & $151.6 \pm 32.6$ \\
\hline$T$ & \multicolumn{2}{|c|}{1.028} & \multicolumn{2}{|c|}{1.269} & \multicolumn{2}{|c|}{1.366} \\
\hline$P$ & \multicolumn{2}{|c|}{.331} & \multicolumn{2}{|c|}{.236} & \multicolumn{2}{|c|}{.205} \\
\hline
\end{tabular}

candidate veins were not available. Data from 5 patients were excluded due to this.

The ASL data were postprocessed by using an automated reconstruction script to generate CBF maps. This included motion correction, pair-wise subtraction between control and labeled images, and the generation of mean-difference images and quantitative $\mathrm{CBF}$ maps.

Regional perfusion in both MCAs was measured by ROIs based on a published template for healthy subjects and patients (Fig 3). ${ }^{20}$ The ROIs of the regional $\mathrm{CBF}$ in each hemisphere were 2100-4000 $\mathrm{mm}^{2}$. The regional CBF of tissue supplied by the MCA was quantified in both hemispheres from the top to bottom sections (15-20 sections), and the data were averaged. The regional $\mathrm{CMRO}_{2}$ was calculated for the tissue supplied by the MCA by using $Y_{\mathrm{v}}$ and the local CBF values.

All patients with acute stroke had lesions located in the region around the MCA. The stroke regions were not included in the ROIs of $\mathrm{CBF}$ measurement.

\section{Statistical Analysis}

All data were analyzed by using SPSS 19.0 (IBM, Armonk, New York). Paired $t$ tests were used to compare $\mathrm{CBF}, \mathrm{OEF}$, and $\mathrm{CMRO}_{2}$ between hemispheres in each subject. The ratios of the mean contralateral/lesion hemispheric $\mathrm{CBF}, \mathrm{OEF}$, and $\mathrm{CMRO}_{2}$ values were calculated and defined as the relative $\mathrm{CBF}$ ( $\mathrm{rCBF}), \mathrm{OEF}$ $(\mathrm{rOEF})$, and $\mathrm{CMRO}_{2}\left(\mathrm{rCMRO}_{2}\right)$ in the patient groups. Analysis of variance and Student-Newman-Keuls tests were conducted to compare rCBF, rOEF, and $\mathrm{rCMRO}_{2}$ among the groups. A $P$ value

in the fifth axis section above or below the phase axis section, and $\Delta z$ is the section thickness $\times 5$. Subsequently, the mean and SD phase values were calculated in the ROI.

The definition of $\varphi_{\mathrm{V}}$ was the darkest pixel or the average of at least 4 dark pixels of similar phase value in the largest vessels (Fig 2). ${ }^{16,19}$ Estimation of $\varphi_{\mathrm{T}}$ was by using the average phase value up to the threshold value (mean \pm 2 SDs) in the ROI. ${ }^{16,19}$ For 1 candidate vein, $\varphi_{\mathrm{V}}$ and $\varphi_{\mathrm{T}}$ were measured 3 times by an experimenter who was blinded to the vascular results and the values were averaged. The $\Delta \varphi_{\text {vein-tissue }}$ value was calculated as $\varphi_{\mathrm{V}}-\varphi_{\mathrm{T}}$. We randomly chose 5 candidate veins on each side of the region in the cerebral cortex supplied by the MCA for each subject, to obtain 5 average $\Delta \varphi_{\text {vein-tissue }}$ values. The veins in the stroke regions were not included in the measurement. Data were excluded if 5 of $<.05$ was statistically significant.

\section{RESULTS}

The largest diameter that an ischemic lesion demonstrated on DWI was $1.8-5.4 \mathrm{~cm}$ (median value, $2.6 \mathrm{~cm}$ ).

The diameter of the vessel at the point of maximal narrowing relative to the normal distal lumen diameter was $0.675 \pm 0.105$ $\mathrm{cm}, 0.371 \pm 0.078 \mathrm{~cm}, 0 \mathrm{~cm}$, and $0.298 \pm 0.254 \mathrm{~cm}$ in groups 1,2 , 3 , and 4 , respectively. The tilt angle of all veins lay in the $10^{\circ}-34^{\circ}$ range (mean values, $25.8^{\circ} \pm 5.1^{\circ}$ ).

For the control subjects, the mean gray matter $Y_{\mathrm{v}}, \mathrm{CBF}, \mathrm{OEF}$, and $\mathrm{CMRO}_{2}$ of the hemispheres supplied by the MCA was $0.629 \pm 0.032(0.579-0.674), 55.7 \pm 9.4(31.9-67.4) \mathrm{mL} \times 100$ 
Table 3: Statistical results of the paired $t$ test for the $\mathrm{CBF}$, OEF, and $\mathrm{CMRO}_{2}$ in the 4 patient subgroups

\begin{tabular}{|c|c|c|c|c|c|c|}
\hline \multirow{3}{*}{ Group 1} & \multicolumn{6}{|c|}{ Contralateral Stenosis } \\
\hline & \multicolumn{2}{|c|}{$\mathrm{CBF}(\mathrm{mL} / 100 \mathrm{~g} / \mathrm{min})$} & \multicolumn{2}{|c|}{ OEF (\%) } & \multicolumn{2}{|c|}{$\mathrm{CMRO}_{2}(\mu \mathrm{mol} / 100 \mathrm{~g} / \mathrm{min})$} \\
\hline & & & & & & \\
\hline & $51.9 \pm 9.5$ & $50.7 \pm 11.2$ & $38.5 \pm 3.9$ & $40.6 \pm 4.2$ & $153.2 \pm 24.0$ & $155.5 \pm 22.9$ \\
\hline$T$ & \multicolumn{2}{|c|}{0.796} & \multicolumn{2}{|c|}{4.027} & \multicolumn{2}{|c|}{0.377} \\
\hline$P$ & \multicolumn{2}{|c|}{.442} & \multicolumn{2}{|c|}{.002} & \multicolumn{2}{|c|}{.713} \\
\hline \multicolumn{7}{|l|}{ Group 2} \\
\hline & $54.6 \pm 5.9$ & $47.9 \pm 9.8$ & $38.4 \pm 1.9$ & $42.6 \pm 3.8$ & $150.3 \pm 28.5$ & $149.4 \pm 46.1$ \\
\hline$T$ & \multicolumn{2}{|c|}{4.146} & \multicolumn{2}{|c|}{4.690} & \multicolumn{2}{|c|}{0.132} \\
\hline$P$ & \multicolumn{2}{|c|}{.002} & \multicolumn{2}{|c|}{.001} & \multicolumn{2}{|c|}{.898} \\
\hline \multicolumn{7}{|l|}{ Group 3} \\
\hline & $54.0 \pm 10.3$ & $37.2 \pm 9.7$ & $37.1 \pm 2.9$ & $44.5 \pm 3.9$ & $154.0 \pm 43.4$ & $125.3 \pm 35.3$ \\
\hline$T$ & \multicolumn{2}{|c|}{6.295} & \multicolumn{2}{|c|}{6.128} & \multicolumn{2}{|c|}{2.926} \\
\hline$P$ & \multicolumn{2}{|c|}{$<.001$} & \multicolumn{2}{|c|}{$<.001$} & \multicolumn{2}{|c|}{.010} \\
\hline \multicolumn{7}{|l|}{ Group 4} \\
\hline & $55.3 \pm 9.5$ & $40.8 \pm 11.8$ & $38.3 \pm 4.1$ & $43.9 \pm 3.5$ & $161.2 \pm 47.4$ & $135.0 \pm 41.3$ \\
\hline$T$ & \multicolumn{2}{|c|}{5.898} & \multicolumn{2}{|c|}{4.626} & \multicolumn{2}{|c|}{2.647} \\
\hline$P$ & \multicolumn{2}{|c|}{$<.001$} & \multicolumn{2}{|c|}{$<.001$} & \multicolumn{2}{|c|}{.018} \\
\hline
\end{tabular}

Table 4: Results of the analysis of variance test for the normal-to-lesion ratio of CBF, OEF, and $\mathrm{CMRO}_{2}$ in the 4 patient subgroups

\begin{tabular}{lcccccc}
\hline & Group 1 & Group 2 & Group 3 & Group 4 & $\boldsymbol{F}$ & $\boldsymbol{P}$ \\
\hline $\mathrm{rCBF}$ & $0.98 \pm 0.11$ & $0.87 \pm 0.11$ & $0.70 \pm 0.17$ & $0.74 \pm 0.17$ & 10.617 & $<.001$ \\
$\mathrm{rOEF}$ & $1.06 \pm 0.05$ & $1.11 \pm 0.08$ & $1.21 \pm 0.14$ & $1.16 \pm 0.14$ & 4.316 & .009 \\
$\mathrm{rCMRO}_{2}$ & $1.03 \pm 0.15$ & $0.98 \pm 0.15$ & $0.84 \pm 0.21$ & $0.86 \pm 0.23$ & 3.041 & .037 \\
\hline
\end{tabular}

gradually increased from group 1 to 3 , coincident with an increase in the degree of angiostenosis. Table 5 lists the Student-Newman-Keuls results comparing the lesion-to-normal ratios in the 4 patient groups.
Table 5: Results of the Student-Newman-Keuls test for the normal-to-lesion ratio of $\mathrm{CBF}, \mathrm{OEF}$, and $\mathrm{CMRO}_{2}$ in the 4 patient subgroups with increasing MCA stenotic severity

\begin{tabular}{cccc}
\hline & rCBF & rOEF & rCMRO $_{2}$ \\
\hline Group 1 & & & \\
$\quad$ Group 2 & $>0.05$ & $>0.05$ & $>0.05$ \\
Group 3 & $<0.05$ & $<0.05$ & $>0.05$ \\
Group 4 & $<0.05$ & $>0.05$ & $>0.05$ \\
Group 2 & & & \\
$\quad$ Group 3 & $<0.05$ & $>0.05$ & $>0.05$ \\
$\quad$ Group 4 & $<0.05$ & $>0.05$ & $>0.05$ \\
Group 3 & & & \\
Group 4 & $>0.05$ & $>0.05$ & $>0.05$ \\
\hline
\end{tabular}

$\mathrm{g}^{-1} \times \min ^{-1}, 37.1 \% \pm 3.2 \%(32.6 \%-42.1 \%)$, and $145.8 \pm 25.1$ (100.6-193.4) $\mu \mathrm{mol} \times 100 \mathrm{~g}^{-1} \times \mathrm{min}^{-1}$, respectively. There were no significant differences in $\mathrm{CBF}, \mathrm{OEF}$, and $\mathrm{CMRO}_{2}$ between the hemispheres (Table 2).

In group 1, significant differences between hemispheres were observed in OEF, but not in $\mathrm{CBF}$ or $\mathrm{CMRO}_{2}$. The OEF in hemispheres with mild MCA stenosis was significantly higher than that in the contralateral hemispheres. Additionally, in group 2, there were significant differences in CBF and OEF, but not in $\mathrm{CMRO}_{2}$ (Table 3). Hemispheres with severe MCA stenosis had a significantly lower CBF and significantly higher OEF than the contralateral hemispheres. Significant differences between hemispheres were observed for CBF, OEF, and $\mathrm{CMRO}_{2}$ in groups 3 and 4 (Table 3). In addition, hemispheres with occluded MCAs had a significantly lower CBF and $\mathrm{CMRO}_{2}$ and significantly higher OEF than the contralateral hemispheres.

There were significant differences in $\mathrm{rCBF}, \mathrm{rCMRO}_{2}$ and rOEF in the 4 patient groups (Table 4). rCBF and $\mathrm{rCMRO}_{2}$ values gradually decreased among groups, but rOEF values

\section{DISCUSSION}

In the present study, the mean venous oxygen saturation, $Y_{\mathrm{v}}$, $(0.629 \pm 0.032)$ of healthy subjects was similar to those in earlier reports $\left(0.64 \pm 0.04,{ }^{6} 0.638 \pm 0.03,{ }^{7} 0.628 \pm 0.053^{21}\right)$ that were measured in the sagittal sinus by using quantitative susceptibility mapping.

Table 6 shows that the range of mean OEF measured by PET has been reported as 35\%-43\%. ${ }^{22-27}$ The OEF $(37.1 \% \pm 3.2 \%)$ calculated in this study was within this range. With a catheterderived arteriovenous approach, $\mathrm{OEF}$ at the right jugular bulb has been calculated as $36 \% \pm 5 \%,{ }^{23}$ which is very close to the OEF calculated in this study.

$\mathrm{CMRO}_{2}$ measured by PET has been reported as ranging from $127 \pm 17.4$ to $156 \pm 22.3 \mu \mathrm{mol} \times 100 \mathrm{~g}^{-1} \times \min ^{-1}$ (Table $6)^{22-27}$ The measurement location was typically global brain regions in these studies. ${ }^{22-25}$ The $\mathrm{CMRO}_{2}$ in gray matter was measured in 2 studies, and values of $156 \pm 22.3$ or $184.9 \pm 20.1$ $\mu \mathrm{mol} \times 100 \mathrm{~g}^{-1} \times \min ^{-1}$ were reported. ${ }^{25,27}$ The ROI in this study incorporated both gray matter and white matter supplied by the MCA. Gray matter CBF is 2.8 times that of white matter, ${ }^{25}$ that is, $\mathrm{CBF}$ in white matter is significantly lower than in gray matter. Therefore, CBF in the ROI is lower than in the gray matter. The CBF decreased, leading to a decrease in $\mathrm{CMRO}_{2}$ in the ROI. This means that $\mathrm{CMRO}_{2}$ found in this study $\left(145.8 \pm 25.1 \mu \mathrm{mol} \times 100 \mathrm{~g}^{-1} \times \mathrm{min}^{-1}\right)$ is lower than gray matter $\mathrm{CMRO}_{2} \cdot{ }^{25,27}$ Furthermore, quantitative susceptibility mapping-based $\mathrm{CMRO}_{2}$ measurements within left and right cortical gray matter regions associated with MCA territories have been reported as $149.3 \pm 27.1$ and $154.8 \pm 37.7$ $\mu \mathrm{mol} \times 100 \mathrm{~g}^{-1} \times \mathrm{min}^{-1} .^{28}$ This finding indicates that the measurement method and $\mathrm{CMRO}_{2}$ values in this study are consistent with quantitative susceptibility mapping-based 
Table 6: Comparison of $\mathrm{OEF}$ and $\mathrm{CMRO}_{2}$ with published literature values determined by using PET for healthy subjects

\begin{tabular}{|c|c|c|c|c|}
\hline Study (Reference) & OEF (Mean) (Range) & $\begin{array}{c}\mathrm{CMRO}_{2} \\
(\mu \mathrm{mol} / \mathrm{min} / 100 \mathrm{~g})\end{array}$ & No. & $\begin{array}{l}\text { Mean Age } \\
\text { (yr) (range) }\end{array}$ \\
\hline Ito et $\mathrm{al}^{22, a}$ & $\begin{array}{c}0.44 \pm 0.06 \\
(0.36 \pm 0.06-0.51 \pm 0.04)\end{array}$ & $147.0 \pm 22.3$ & 70 & $53.1(18-77)$ \\
\hline Hattori et $\mathrm{al}^{23, a}$ & $\begin{array}{c}0.39 \pm 0.06 \\
(0.30-0.51)\end{array}$ & $127.0 \pm 17.4$ & 16 & $35(21-46)$ \\
\hline Coles et $\mathrm{al}^{24, \mathrm{a}}$ & $0.42 \pm 0.04$ & $124.8 \pm 22.3$ & 7 & $30(18-60)$ \\
\hline Ibaraki et al ${ }^{25, b}$ & $0.35 \pm 0.06$ & $156.0 \pm 22.3$ & 8 & NA (21-24) \\
\hline Bremmer et $\mathrm{al}^{26, a}$ & $0.43 \pm 0.06$ & $135.9 \pm 8.9$ & 7 & $69(57-80)$ \\
\hline Kudomi et al ${ }^{27, b}$ & $0.39 \pm 0.05$ & $184.9 \pm 20.1$ & 7 & 25.3 (NA) \\
\hline
\end{tabular}

Note:-NA indicates not available.

${ }^{a}$ Across subjects/brain regions.

${ }^{\mathrm{b}}$ Gray matter values.

$\mathrm{CMRO}_{2}$ measurements, ${ }^{28}$ suggesting the robustness of these methods for the measurement of OEF and $\mathrm{CMRO}_{2}$.

The original phase-based regional oxygen metabolism method used a multiecho sequence. ${ }^{16}$ Multiecho phase values fit a straight line that is a phase against TE, and a new phase for a TE is extrapolated from the straight line. The difference between the new phase and the measured phase is due to noise. Multiecho sequences remove the effect of noise on phase measurements. The SD in $Y_{\mathrm{v}}$ estimates due to noise is $<5 \%$ of oxygen saturation, with a signal-to-noise ratio is as low as $10,{ }^{16}$ whereas an ordinary phase image has an average SNR in the range of 40-70. This means that thermal noise within this SNR range leads to proportionately small error values. In addition, multiecho sequences require triple the calculations of singleecho sequences, which makes it difficult to apply the former in clinical practice.

We reconstructed the magnitude and phase images by using a single-echo sequence. The mean $Y_{\mathrm{v}}(0.629 \pm 0.032)$ in this study is similar to the value $(0.638 \pm 0.03)$ measured in the sagittal sinus by using a dual-echo sequence in healthy subjects. ${ }^{7}$ Furthermore, the $\mathrm{OEF}$ and $\mathrm{CMRO}_{2}$ values of the healthy subjects in this study are in agreement with the values determined by using PET or MR imaging. ${ }^{22-28}$ These results demonstrate that the present method of OEF measurement is accurate; therefore, OEF measured by a single-echo sequence is simple and useful.

An earlier study used standard approximate values for Hct and hemoglobin ${ }^{16,28,29}$; however, Hct and hemoglobin were calculated directly from blood measurements in this study.

At present, there is controversy over the value of $\Delta \chi_{\mathrm{do}}{ }^{16}{ }^{16}$ The 2 reported values $(0.27$ and $0.18 \mathrm{ppm})$ lead to a difference of approximately $13 \%$ in $\mathrm{SvO}_{2}$ estimates. ${ }^{7}$ We adopted $0.27 \mathrm{ppm}$ in this study on the basis of recently published research. ${ }^{15}$

The susceptibility reproduced by the long-cylinder approximation has excellent accuracy and precision when the length of a vein exceeds $6 \times$ its diameter ${ }^{8}$; therefore, a vein with a length of at least $6 \times$ its diameter can be used in the long-cylinder model in MR susceptometry. On the basis of our observations, this standard is easy to meet in the veins of the brain.

All vessels were not parallel to the $\mathrm{B}_{0}$ field, and the tilt angle was not equal to zero. Veins thread tortuously through the brain sulcus. Therefore, significant lengths that are parallel to the $B_{0}$ field are unlikely.
A $32 \times 32$ Hanning filter was used to enhance the phase image in this study. This resulted in $<1 \% Y_{\mathrm{v}}$ bias. $^{16}$ Therefore, the effects on the quantification of the vein-tissue phase caused by the $32 \times$ 32 Hanning filter can be safely ignored.

To the best of our knowledge, no previous studies have investigated changes in $\mathrm{CBF}, \mathrm{OEF}$, and $\mathrm{CMRO}_{2}$ based on the severity of MCA stenosis. With the help of HR-T2WI, we measured and classified the degree of MCA stenosis, which has not been published previously. Moreover, ASL and SWI are noninvasive examinations compared with PET, making these techniques attractive for a clinical setting.

As shown in Table 3, CBF significantly decreased in groups 2 and 3. In addition, OEF increased from groups 2 through 4, coincident with the severity of the MCA stenosis. This increase is a compensatory mechanism to counteract the decrease in CBF and stabilize cerebral oxygen metabolism, indicating a self-regulatory mechanism in the brain.

Tables 4 and 5 show that a small increase in rOEF was present in patients with severe MCA stenosis (group 2) compared with patients with mild MCA stenosis (group 1). Most interesting, rOEF was significantly higher in patients with occlusive MCA (group 3) compared with patients with mild MCA stenosis. This result demonstrates that collateral circulation can compensate for the shortage in CBF in patients with mild MCA stenosis, but not in those with severe MCA stenosis. Moreover, in mild or severe MCA stenosis, the $\mathrm{CMRO}_{2}$ of the hemisphere with MCA stenosis was similar to or slightly lower than the contralateral $\mathrm{CMRO}_{2}$. This difference indicates that an increase in the OEF can balance a decrease in $\mathrm{CBF}$ in the presence of mild or severe MCA stenosis, ultimately maintaining brain oxygen availability. Conversely, when an occlusion was present in the MCA, the $\mathrm{CMRO}_{2}$ of the affected hemisphere was significantly lower than that of the contralateral hemisphere. These findings indicate that the presence of an occlusion prevents an increase in OEF to offset the decrease in CBF, leading to a decrease in $\mathrm{CMRO}_{2}$. This decrease in $\mathrm{CMRO}_{2}$ can disrupt normal cellular function or metabolism and ultimately lead to cell death. Furthermore, a decrease in $\mathrm{CMRO}_{2}$ indicates that the OEF has reached a maximal or nearly maximal level. Consequently, the risk of stroke is higher in patients with severe stenosis or an occluded MCA than in the presence of mild stenosis.

The CBF in stroke regions was significantly lower than that in the normal brain. There can be significant measurement errors if the stroke area is incorporated in the ROI; therefore, we avoided the stroke region when measuring CBF in patients with acute stroke. We observed that the OEF and $\mathrm{CMRO}_{2}$ significantly increased and decreased, respectively, in the territory of the occluded MCA during acute stroke. This observation is consistent with the findings of previous studies by using PET. ${ }^{30-33}$ Tables 3-5 show that the CBF, OEF, and $\mathrm{CMRO}_{2}$ values of patients with acute stroke were similar to those of patients in group 3, but not group 2. Conversely, the degree of the angiostenosis in group 4 was similar to that of group 2, but 
not group 3. Table 5 shows that there was a significant difference in $\mathrm{rCBF}$ between groups 2 and 4. The OEF may have reached its maximum value because of the markedly decreased CBF in group 4, which consequently led to the acute stroke. Most patients in group 3 had neurologic symptoms, such as headache. Research has revealed that there is a high incidence of stroke in patients with an increased OEF due to an occluded carotid artery. ${ }^{34}$ As a result, patients with an increased OEF in group 3 may have been close to having a stroke.

This study has several limitations. First, although we simplified the method as much as possible, it remains complex and difficult to master for clinician doctors. Second, the controversy regarding the value of $\Delta \chi_{\text {do }}$ remains. Third, this method can only obtain measurements for the entire MCA territory, not the regional OEF in the infarction area or penumbra.

\section{CONCLUSIONS}

The study obtained 2 primary results: 1 ) The OEF gradually increased from group 1 through 3 . When the increased OEF compensated for a decreased $\mathrm{CBF}, \mathrm{CMRO}_{2}$ remained at a normal level; however, an occluded MCA led to a reduction in both CBF and $\mathrm{CMRO}_{2}$. 2) The OEF and $\mathrm{CMRO}_{2}$ were significantly increased and decreased, respectively, in the territory around the occluded MCA in acute stroke.

\section{REFERENCES}

1. Derdeyn CP, Videen TO, Yundt KD, et al. Variability of cerebral blood volume and oxygen extraction: stages of cerebral haemodynamic impairment revisited. Brain 2002;125:595-607 CrossRef Medline

2. Derdeyn CP, Videen TO, Simmons NR, et al. Count-based PET method for predicting ischemic stroke in patients with symptomatic carotid arterial occlusion. Radiology 1999;212:499-506 CrossRef Medline

3. Derdeyn CP, Videen TO, Grubb RL Jr, et al. Comparison of PET oxygen extraction fraction methods for the prediction of stroke risk. J Nucl Med 2001;42:1195-97 Medline

4. Yamauchi H, Higashi T, Kagawa S, et al. Is misery perfusion still a predictor of stroke in symptomatic major cerebral artery disease? Brain 2012;135:2515-26 CrossRef Medline

5. Jain V, Langham MC, Floyd TF, et al. Rapid magnetic resonance measurement of global cerebral metabolic rate of oxygen consumption in humans during rest and hypercapnia. J Cereb Blood Flow Metab 2011;31:1504-12 CrossRef Medline

6. Jain V, Langham MC, Wehrli FW. MRI estimation of global brain oxygen consumption rate. J Cereb Blood Flow Metab 2010;30:1598607 CrossRef Medline

7. Fan AP, Bilgic B, Gagnon L, et al. Quantitative oxygenation venography from MRI phase. Magn Reson Med 2014;72:149-59 CrossRef Medline

8. Langham MC, Magland JF, Epstein CL, et al. Accuracy and precision of MR blood oximetry based on the long paramagnetic cylinder approximation of large vessels. Magn Reson Med 2009;62:333-40 CrossRef Medline

9. Fujima N, Kudo K, Terae S, et al. Non-invasive measurement of oxygen saturation in the spinal vein using SWI: quantitative evaluation under conditions of physiological and caffeine load. Neuroimage 2011;54:344-49 CrossRef Medline

10. Zaitsu Y, Kudo K, Terae S, et al. Mapping of cerebral oxygen extraction fraction changes with susceptibility-weighted phase imaging. Radiology 2011;261:930-36 CrossRef Medline

11. Günther M, Oshio K, Feinberg DA. Single-shot 3D imaging techniques improve arterial spin labeling perfusion measurements. Magn Reson Med 2005;54:491-98 CrossRef Medline
12. Vidorreta M, Wang Z, Rodríguez I, et al. Comparison of 2D and 3D single-shot ASL perfusion fMRI sequences. Neuroimage 2013;66: 662-71 CrossRef Medline

13. Derdeyn CP, Powers WJ, Grubb RL Jr, et al. Hemodynamic effects of middle cerebral artery stenosis and occlusion. AJNR Am J Neuroradiol 1998;19:1463-69 Medline

14. Tanaka M, Shimosegawa E, Kajimoto K, et al. Chronic middle cerebral artery occlusion: a hemodynamic and metabolic study with positron-emission tomography. AJNR Am J Neuroradiol 2008;29: 1841-46 CrossRef Medline

15. Jain V, Abdulmalik O, Propert KJ, et al. Investigating the magnetic susceptibility properties of fresh human blood for noninvasive oxygen saturation quantification. Magn Reson Med 2012;68:863-67 CrossRef Medline

16. Fan AP, Benner T, Bolar DS, et al. Phase-based regional oxygen metabolism (PROM) using MRI. Magn Reson Med 2012;67:669-78 CrossRef Medline

17. Mildner T, Trampel R, Möller HE, et al. Functional perfusion imaging using continuous arterial spin labeling with separate labeling and imaging coils at 3 T. Magn Reson Med 2003;49:791-95 CrossRef Medline

18. Binnewijzend MA, Kuijer JP, Benedictus MR, et al. Cerebral blood flow measured with 3D pseudocontinuous arterial spin-labeling MR imaging in Alzheimer disease and mild cognitive impairment: a marker for disease severity. Radiology 2013;267:221-30 CrossRef Medline

19. Fujima N, Kudo K, Terae S, et al. Spinal arteriovenous malformation: evaluation of change in venous oxygenation with susceptibility-weighted MR imaging after treatment. Radiology 2010;254:891-99 CrossRef Medline

20. Chalela JA, Alsop DC, Gonzalez-Atavales JB, et al. Magnetic resonance perfusion imaging in acute ischemic stroke using continuous arterial spin labeling. Stroke 2000;31:680-87 CrossRef Medline

21. Xu F, Ge Y, Lu H. Noninvasive quantification of whole-brain cerebral metabolic rate of oxygen (CMRO2) by MRI. Magn Reson Med 2009;62:141-48 CrossRef Medline

22. Ito H, Kanno I, Kato C, et al. Database of normal human cerebral blood flow, cerebral blood volume, cerebral oxygen extraction fraction and cerebral metabolic rate of oxygen measured by positron emission tomography with 150 -labelled carbon dioxide or water, carbon monoxide and oxygen: a multicentre study in Japan. Eur J Nucl Med Mol Imaging 2004;31:635-43 CrossRef Medline

23. Hattori N, Bergsneider M, Wu HM, et al. Accuracy of a method using short inhalation of $(15) \mathrm{O}-\mathrm{O}(2)$ for measuring cerebral oxygen extraction fraction with PET in healthy humans. J Nucl Med 2004;45: 765-70 Medline

24. Coles JP, Fryer TD, Bradley PG, et al. Intersubject variability and reproducibility of 150 PET studies. J Cereb Blood Flow Metab 2006; 26:48-57 CrossRef Medline

25. Ibaraki M, Miura S, Shimosegawa E, et al. Quantification of cerebral blood flow and oxygen metabolism with 3-dimensional PET and ${ }^{15} \mathrm{O}$ : validation by comparison with 2 -dimensional PET. J Nucl Med 2008;49:50-59 Medline

26. Bremmer JP, van Berckel BN, Persoon S, et al. Day-to-day testretest variability of $\mathrm{CBF}, \mathrm{CMRO}$, and $\mathrm{OEF}$ measurements using dynamic 150 PET studies. Mol Imaging Biol 2011;13:759-68 CrossRef Medline

27. Kudomi N, Hirano $\mathrm{Y}$, Koshino $\mathrm{K}$, et al. Rapid quantitative $\mathrm{CBF}$ and CMRO(2) measurements from a single PET scan with sequential administration of dual (15)O-labeled tracers. J Cereb Blood Flow Metab 2013;33:440-48 CrossRef Medline

28. Zhang J, Liu T, Gupta A, et al. Quantitative mapping of cerebral metabolic rate of oxygen (CMRO2) using quantitative susceptibility mapping (QSM). Magn Reson Med 2015;74:945-52. CrossRef Medline

29. Qin Q, Grgac K, van Zijl PC. Determination of whole-brain oxygen extraction fractions by fast measurement of blood $\mathrm{T}(2)$ in

AJNR Am J Neuroradiol 37:607-14 Apr 2016 www.ajnr.org

613 
the jugular vein. Magn Reson Med 2011;65:471-79 CrossRef Medline

30. Donswijk ML, Jones PS, Guadagno JV, et al. T2*-weighted MRI versus oxygen extraction fraction PET in acute stroke. Cerebrovasc Dis 2009;28:306-13 CrossRef Medline

31. Guadagno JV, Jones PS, Fryer TD, et al. Local relationships between restricted water diffusion and oxygen consumption in the ischemic human brain. Stroke 2006;37:1741-48 CrossRef Medline

32. Sobesky J, Zaro Weber O, Lehnhardt FG, et al. Does the mismatch match the penumbra? Magnetic resonance imaging and positron emission tomography in early ischemic stroke. Stroke 2005;36: 980-85 CrossRef Medline

33. Heiss WD, Sobesky J, Hesselmann V. Identifying thresholds for penumbra and irreversible tissue damage. Stroke 2004;35:2671-74 CrossRef Medline

34. Derdeyn CP, Yundt KD, Videen TO, et al. Increased oxygen extraction fraction is associated with prior ischemic events in patients with carotid occlusion. Stroke 1998;29:754-58 CrossRef Medline 